\section{Questión}

Periodismo / Comunicación ISSN 1669-6581
- Av. $44 \mathrm{~N}^{\circ} 676,1^{\circ}$ piso

CP 1900 - La Plata - Argentina

www.perio.unlp.edu.ar/question

\title{
INFORMACIÓN Y PANDEMIA. APUNTES MARXISTAS PARA UNA COMUNICOLOGÍA POSIBLE Y NECESARIA
}

\section{INFORMATION AND PANDEMIC. MARXIST NOTES FOR A POSSIBLE AND NECESSARY COMMUNITY}

Francisco Sierra Caballero / www.franciscosierraballero.net

Catedrático de Teoría de la Comunicación de la Universidad de Sevilla. Director de la Sección de Comunicación y Cultura de la Fundación de Investigaciones Marxistas, en la actualidad preside la Unión Latina de Economía Política de la Información, la Comunicación y la Cultura (ULEPICC) y es miembro activo de la RED TRANSFORM de la UE, y de la

Asociación Española de Investigación en Comunicación (AE-IC). Ha dirigido CIESPAL (2014-2017) y fundado y presidido CONFIBERCOM, entre otras organizaciones científicas internacionales. Autor, entre otras obras, de "Políticas

de Comunicación y Educación. Crítica y Desarrollo de la Sociedad del Conocimiento" (Gedisa, Barcelona, 2006) o "Introducción a la Comunicología" (ACCI, Madrid, 2019) dirige el Grupo Interdisciplinario de Estudios en Comunicación,

Política y Cambio Social (COMPOLITICAS) y forma parte del Instituto Andaluz de Investigación en Comunicación y

Cultura (INACOM). Ha dirigido numerosos proyectos europeos e iberoamericanos de investigación, con una obra reconocida internacionalmente y traducida, entre otros idiomas, al inglés, francés, italiano y portugués, Su último libro, recientemente editado, lleva por título "Marxismo y Comunicación. Teoría Crítica de la Mediación Social" (Siglo XXI,

Madrid, 2020).

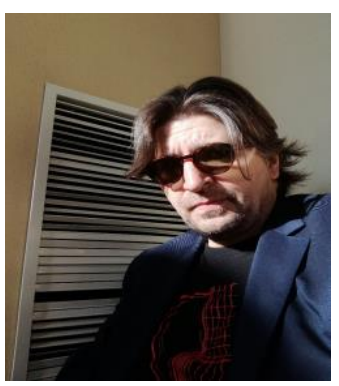


Todo avatar del pensamiento está sujeto al plano de la inmanencia y a las vicisitudes propias del acontecer social. En particular, la crisis de confinamiento y lucha contra el coronavirus me alcanzó terminando de corregir las galeradas de $\mathrm{mi}$ último libro MARXISMO $Y$ COMUNICACIÓN. Teoría Crítica de la Mediación Social, un esfuerzo teórico por ofrecer al lector las líneas maestras de desarrollo de la teoría marxista sistematizando algunos de los principales aportes de la visión materialista que han contribuido al pensamiento emancipador en comunicación. El ensayo, además de rendir tributo al sabio de Tréveris, fue escrito con la intención de aportar elementos básicos para una necesaria crítica materialista de la mediación social y alumbrar una evidencia inexcusable en tiempos de libre comercio: la dimensión política de toda mediación cognitiva. En palabras de Douglas Kellner, la Política y la Economía, como matriz de abordaje de la Comunicación, significa que la producción y distribución de la cultura tiene lugar en un sistema económico particular, en una forma de producción y reproducción social específica que no puede ni debe ser eludida si algún sentido tiene la ciencia desde el punto de vista social. $\mathrm{Y}$ he aquí que en la corrección de pruebas de imprenta uno ha de confrontar la dimensión pública de la actual crisis de salud y económica que amenaza el futuro del capitalismo y de la propia civilización. En este marco, una vez más es ineludible aprender a pensar de otro modo la comunicación. La conexión entre los aspectos culturales y comunicativos, los tecnológicos y económicos, y los político-informativos y tecno-estéticos que están en la base del modelo de análisis marxista nos puede ayudar a pensar las alternativas democráticas en un horizonte de progreso amenazado por las distopías y el discurso de la cultura zombie.

Frente a la marginalidad de la teoría crítica, situaciones como esta nos sitúan ante el reto de aprender a pensar, reflexivamente, retomando la capacidad de interrogación para denunciar los presupuestos del sistema de relaciones dominantes en el campo de la información y la comunicación, una suerte, en fin, de análisis sintomático que hace emerger lo real, proyectando nuevas prácticas instituyentes, un nuevo pensamiento y praxis social para pasar de la cultura de la resistencia a la razón emancipadora que ha de acompañar toda práctica transformadora en momentos de crisis como el que vivimos con la pandemia.

Considerando los diferentes niveles de acción, en este marco resulta revelador tanto los problemas de orden práctico, como la lógica desinformativa de la posverdad, que los medios oficiales vienen desplegando por su adherencia a los modelos de representación ideológica 
presentes también en la práctica teórica hegemónica en la Comunicología. Más allá y más acá de Marx, la revisión de las lecturas preponderantes sobre la crisis de salud pública es una oportunidad en este sentido para tratar, desde nuevos prismas, la crisis de gestión del Estado y en general del capitalismo en la protección de los sectores más vulnerables. Por ejemplo, es posible, desde una visión marxista, despejar cierto desdibujamiento que sobre la teoría crítica han querido proyectar culturalistas o funcionalistas reciclados desde la posmodernidad, al identificar toda lectura materialista con el modelo economicista de la vulgata al uso sobre las teorías del control social frente a la compleja lectura propia de un pensamiento relacional que tiende a pensar la realización de la lógica del valor y el fetichismo de la mercancía desde una definición materialista consustancial a toda mediación social. Así, por ejemplo, si acometemos una interpretación más amplia del fenómeno global del coronavirus desde el punto de vista de la inmovilización de la población ante procesos de movilización de población, como las migraciones, o la acción colectiva que en países como España se han venido articulando, como la Marea Blanca, en defensa de la sanidad pública, las conclusiones difieren notablemente. Vaya por delante que la propia Comunicología apenas ha cultivado el conocimiento en ambos fenómenos de relevancia para ilustrar el proceso de reproducción social ampliado en el capitalismo.

Hablamos de dos líneas bien distintas de trabajo, aunque ambas, qué duda cabe, comparten la lógica de desborde que ilustra, sintomáticamente, la actual crisis del capitalismo. Pero el desarrollo de ambas líneas ha sido dispar. En los estudios sobre movimientos sociales, ha habido un resurgimiento tras décadas de olvido y marginalidad en el campo académico, pero cabe observar, paradójicamente, que en la Comunicología la atención sobre las diversas dimensiones de la acción colectiva ha sido considerablemente menor si pensamos, comparativamente, en otras ciencias sociales como la Sociología o la Antropología. Y ello incluso en contextos como el nuestro, pese a la centralidad que tiene, desde el punto de vista del cambio social, el nuevo ciclo de protestas para explicar los procesos históricos que estamos viviendo. Ello se debe, creo, a un doble condicionamiento: el mediocentrismo que elude o ha dejado de lado históricamente otras prácticas culturales al margen del proceso informativo, y como es notorio el desplazamiento de la agenda de investigación de una perspectiva crítica a un enfoque neofuncional de corte culturalista. Recuerdo un editorial de mi colega argentino Carlos Mangone en la Revista de Comunicación y Cultura de la UBA sobre la evolución del 
campo iberoamericano y la renuncia al compromiso intelectual de los académicos por un prurito de supuesta cientificidad. $Y$ ratifico lo dicho o resumido en su ensayo. De hecho, lo poco que cabe leer en nuestro ámbito tiende a reproducir la lógica del espíritu positivo de este tiempo: un acendrado empirismo de descripción de experiencias y procesos de participación en movimientos sociales $y$, por otra parte, la fragmentación o aislamiento de los distintos movimientos, abordados cuando se interesa la investigación por ellos de manera particular (ecologista, feminista, campesino) con una nula voluntad de articulación y teorización sobre el interfaz nuevos medios y procesos de transformación social. $Y$ ello pese a la importancia que tiene la necesaria conceptualización de la cultura digital en las formas y procesos de activismo que se pueden observar a este respecto. Y que, por cierto, podrían ayudar a ilustrar, desde el campo de la comunicación, lo que Williams denominaba estructura de sentimiento. En el caso de los estudios de migración, estas limitaciones son si cabe más gravosas. Primero por ser como es la cultura latina un ecosistema hibridado y, al tiempo, por reproducir la división del trabajo intelectual: estudiando desde el Norte los procesos de mestizaje y movimiento de población como meras culturas receptoras sin que se cuestione la matriz colonial que esta geopolítica del conocimiento implica. Bien es cierto, que los Estudios Culturales han puesto en valor la diversidad y riqueza de las matrices culturales en América Latina, pero falta avanzar, con el giro decolonial, un trabajo de reformulación de la modernidad capitalista desde lo que Bolívar Echeverría denomina la lógica del ethos barroco. Esta lectura, del pensamiento de la liberación, que anticipa Enrique Dussel, está por hacer en comunicación y significaría repensar la migración desde una visión histórica y política de los procesos trasterrados de movimientos de población, empezando por la resistencia de las culturas indígenas y las figuras denostadas en la narrativa dominante como el mestizo de cara a imaginar una suerte de episteme de la frontera que analice las redes de intercambio y apropiación de los códigos culturales considerando la dimensión geopolítica e instituyente de la creatividad que entraña en las culturas populares las formas de vida resultantes de la mezcla, del contagio, de la síntesis y proceso constituyente de las identidades descentradas y periféricas que habitan el universo de la subalternidad. Frente a esta exigencia teórica y política, en congruencia con lo que somos y nuestra cultura e historia en común, tenemos una investigación comunicacional que, lejos de asumir esta dimensión transformadora, y pese a los avances del movimiento indígena y sus aportes para pensar radicalmente la comunicación, aplaude y respalda el golpismo mediático y 
la cultura racista del neofascismo evangélico, tal y como hemos visto en Bolivia o Brasil. La cuestión por tanto ahora, en este horizonte histórico, sería preguntarnos qué ha hecho la academia, qué posición epistemológica ha adoptado la inteligencia comunicacional y por qué se ha plegado a una lectura, digamos, administrativa de matriz colonial que en momentos de ciris como el actual dejan de tener razón de ser, pierden, en fin toda la legitimidad. Sirva como ilustración de esta deriva la irrelevancia que vienen teniendo en la academia los estudios sobre Comunicación Indígena. Y ello pese a la importancia que han adquirido en las últimas décadas. En Bolivia, Chile o Ecuador, como antaño en México, el movimiento indígena viene desbordando los marcos tradicionales de representación y gobierno. Puede decirse que, desde los años noventa, ha habido un proceso de articulación y organización social que ha revolucionado la región. Los procesos progresistas en América Latina no son comprensibles sin el movimiento indígena. $Y$ este protagonismo político también ha tenido traslación en la comunicación popular. Desde el I Encuentro Intergaláctico, convocado por el EZLN en Chiapas, la articulación de redes de información y comunicación comunitaria del movimiento indígena ha sido además de creativo un espacio autónomo para pensar la comunicación. Y ello ha marcado la agenda de nuevos debates en las Congresos de Abya Yala en este siglo XXI del Cauca a La Paz, de Oaxaca a la Amazonía brasileña, dando forma a un nuevo pensamiento comunicacional, como hace tiempo ya propuso en vida priorizar Luis Ramiro Beltrán, estudioso de las formas precolombinas de comunicación y auténtico impulsor de los estudios en la materia tanto en la teoría como en la práctica. En resumen, de un tiempo a esta parte, las condiciones son óptimas para construir un nuevo paradigma. Hoy por ejemplo tenemos las universidades de la tierra y la academia, aunque tímidamente, empieza a ocuparse en serio del diálogo de saberes, ya lo lleva haciendo desde unos años, aprendiendo de la comunicación del pueblo mapuche, de las experiencias de las comunidades quechuas y aymaras, de las formas de ser y representar de las culturas indígenas. Pienso en colegas de la Universidad Andina, de UNIMINUTO, de la UFRO en Chile, de la UnB en Brasil, de compañeros de Salta, además de la valiosa labor histórica de SIGNIS, ALAI, ALER, FARCO y tantas otras organizaciones de radio y medios comunitarios que vienen interviniendo sobre el terreno desde una filosofía de la praxis. En este empeño, hicimos un intenso trabajo en CIESPAL. $Y$ hemos venido insistiendo antes $y$ después en la necesidad de una Comunicologia del Sur pensada desde la experiencia de la comunicación indígena en la que hay ya trabajos de relevancia para avanzar otra agenda de 
investigación en comunicación. Creo, sinceramente, que en este sendero conviene seguir avanzando, más ahora que se impone la agenda restauradora y reaccionaria de una comunicación racista, segregacionada y cosmopaleta, por más que se nos hable de la modernidad líquida, la sociedad red o la comunicación inteligente y móvil, en un tiempo, paradójicamente, de confinamiento.

En este escenario, vindicar la comunicación popular indígena pareciera una lectura a contrapelo de la historia, como dijera Benjamin, pero, a nuestro juicio, más bien puede ayudarnos a contextualizar adecuadamente los retos de la revolución digital de ejercicio de ciudadanía en la era de la videovigilancia global, aun por razones de salud pública. Si el problema de la comunicación y la cultura en nuestro tiempo es la lucha por el código, por la apropiación de lo inmaterial, objeto a su vez de un intensivo intercambio, el reconocimiento y valoración de las diversas formas de autoproducción (de las favelas y el sector terciario informal a los jóvenes conectados para ejercer la libertad de intercambio) que hoy reivindican y practican los nuevos actores políticos en la red, exige, a nuestro entender, que problematicemos estos procesos para garantizar una esfera pública autónoma que reconozca las dimensiones productivas de la ciudadanía frente al modelo tradicional de centralización y apropiación de los bienes comunes, empezando por la propia comunicación. En este sentido, es preciso reconocer la emergencia de lo que el profesor Galindo denominó la primera erupción visible, la proyección de nuevas prácticas o culturas políticas. De Obama a Trump, de Facebook a Twitter, de la cultura underground situacionista al movimiento Yo Soy132 o la guerrilla semiótica de la cibercultura en el 15M, en España, las nuevas tecnologías de la información han modificado, estructuralmente, las formas de organización y acción política. Algunos sitúan el punto de inflexión en el levantamiento zapatista de 1994, pero sabemos que existe una amplia experiencia acumulada, desde la década de los sesenta, en materia de comunicación popular y alternativa. Las experiencias que hoy proliferan en la era digital no hacen sino actualizar las formas de interlocución que los grupos subalternos han procurado articular a lo largo de la historia para favorecer procesos de empoderamiento y resistencia. Existen por tanto líneas de continuidad, tanto como discontinuidades, considerando la dimensión disruptiva de la tecnología, en la producción de la mediación social contemporánea. Desde el punto de vista de las lógicas propias de la cultura digital y la pertinencia por consiguiente de una perspectiva materialista, ello implica, hoy más que nunca, la necesidad de 
perfilar nuevas matrices y un pensamiento propio a partir de un enfoque productivo capaz de romper con la racionalidad binaria y externa del mediactivismo como un simple proceso de oportunidad política. En Latinoamérica, venimos además constatando, a este respecto, que existen diferentes prácticas políticas inéditas y singulares, poco o nada consideradas por las fuerzas tradicionales de la izquierda, y menos aún por la academia, pese a las evidencias que muestran que este tipo de formas de intervención proyectan la producción de otra narrativa y modelo de organización de la comunicación. Por ello, constituimos desde COMPOLITICAS (www.compoliticas.org) el Grupo de Trabajo sobre Tecnopolítica, cultura digital y ciudadanía (CLACSO), y la red de pensamiento y activismo social TECNOPOLITICAS (http://www.tecnopoliticas.org/) sabedores que toda política alternativa pasa, en términos gramscianos, por un esfuerzo de pedagogía democrática y articulación. En el proyecto CIBERMOV (www.cibermov.net) proponemos, en esta línea, un retorno a Atenas, parafraseando el ensayo sobre democracia participativa del filósofo José Luis Moreno Pestaña (2019), a la hora de definir un abordaje y perspectiva transformadora del nuevo ecosistema informativo desde el punto de vista de las políticas públicas y la participación social. La hipótesis de partida es la pertinencia de una actualización de los mecanismos de la democracia antioligárquica conectando experiencias históricas existentes, de Pericles a nuestro tiempo, con las formas emergentes de interacción en torno a los nuevos dispositivos de codificación social. En otras palabras, necesitamos problematizar las nociones al uso de producción del espacio público y el ágora, considerando las posibilidades y limitaciones de la lógica de reproducción social, justo ahora que paradójicamente estamos encerrados en casa y con miedo a construir lo común. La revolución digital no solo ha cambiado el modo de consumir y proyectar nuestras identidades. El campo político ha sido radicalmente alterado por las redes sociales, transformando las formas de interlocución y la propaganda. El problema es que estas transformaciones no han ido acompañadas de un marco normativo que regule y proteja los derechos ciudadanos. Prevalece, antes bien, una suerte de lógica de No Man's land, un vacío o territorio de nadie en el que se impone la disputa sin reglas replicándose una peligrosa dinámica de confrontación. Pensemos en la ultraderecha, a lo Steve Bannon, o en la lógica Bolsonaro de bulos y desinformación. Es sabido que allí donde no existe protección legal, donde no quedan claramente definidos derechos y obligaciones, impera la ley del más fuerte, la de aquellos que disponen de bots y recursos para imponer su voz en lo que el filósofo alemán 
Jürgen Habermas hace tiempo definió como privatización del espacio por la que se confunde la opinión pública con la publicación sobrerrepresentada de quienes tienen el poder de imponer su discurso: como decimos en Andalucía, se está imponiendo una cultura de palmeros, una opinión pública por aclamación. Tómese en cuenta además que la cultura de la era Instagram ha modificado sustancialmente los imaginarios y experiencia de los actores sociales. En este marco, hemos de pensar necesariamente los cambios en la cultura política que introduce la revolución digital. Y en este empeño estamos con el proyecto de investigación. Podríamos en este sentido ver cómo las relaciones de intercambio, con el confinamiento, han generado redes de solidaridad y compromiso, formas de comunicarse y compartir inéditas, e incluso coberturas periodísticas no imaginadas antes por razones de seguridad y protección de los trabajadores de los medios.

Sería largo y prolijo destacar todos y cada uno de los cambios que la crisis estructural que vive el sistema ha proyectado, así como los aportes que el campo académico viene formulando a este respecto. Como estos apenas son unos apuntes, escritos sobre lo ya pensado, permita el lector al menos destacar dos: la recuperación de la dimensión inmanente de la comunicación, consustancial a la revolución de la vida cotidiana que introduce la galaxia internet y, sobremanera, la vigencia de una Comunicología de la Praxis. Si me permite el lector, voy a centrarme en este punto que para mí es el principal hito de la ola de protestas y activismo digital que vivimos antes y durante la crisis del coronavirus. Quienes siempre hemos defendido que la Comunicología debe pensar para transformar y comunicar para cambiar la vida nos enfrentamos hoy a pensar el Capitalismo Selfie como un problema de construcción social y transformación histórica en virtud de nuevos imaginarios instituyentes: del 15M a la lucha constituyente en Chile, de Occupy a las nuevas estéticas del carnaval del movimiento feminista, de la marea blanca a la solidaridad con el personal sociosanitario y la clase trabajadora que ha hecho posible el mantenimiento de la vida en momentos de parálisis y confinamiento. En todas y cada una de estas experiencias se observa que, al menos embrionariamente, se conforma un nuevo sensorium, una nueva forma de la mediación social con las que comprender las lógicas y códigos culturales de la ciudadanía. Esta nueva sensibilidad y cultura política se distingue por una elevada plasticidad manierista, una tendencia neobarroquista marcada por la predominancia de la lógica de las máscaras, la elocuencia y proyección espectacular de los cuerpos y los signos propios de un capitalismo 
excedentario. La forma de representación carnavalizada de los movimientos sociales y ciberactivistas remite, en este sentido, a una nueva economía moral de la multitud que tiende a recodificar, como en el siglo de oro, las contradicciones entre lo posible y lo necesario, entre la lógica del vil metal y el espíritu. Así, la importancia del flashback en la cultura mediática, ya analizada por Adorno y Horkheimer, da cuenta hoy de la importancia de la memoria y las políticas de representación que no tanto son un retorno a lo identitario sino más bien procesos de adaptación creativa y resistencia que problematizan la relación del sujeto con su tiempo y con la cultura dominante. No olvidemos que, como explica Deleuze, la imagen-tiempo sustituye en el cine moderno a la imagen-movimiento de la memoria clásica. La mediación de la nueva cultura informativa afecta al eje perceptivo, al eje afectivo y, claro está, a la función proactiva del sujeto. El tiempo -dejó escrito Eugenio Trías- siempre se alza en la modernidad, en el cine nuevo, por ejemplo, reteniendo el movimiento, en función de lo que Moles denominaba cultura conservadora o registro, de una acción rota, una oquedad que permite la emergencia de la memoria involuntaria, o de capas dispersas de ésta, o una conversión del actor y del espectador en auténticos videntes a fuerza de la dinámica de la plusvalía semántica o la semiosis ilimitada. Descubrir y situar en su contexto esta potencialidad creativa, como enseñara Castoriadis, se nos antoja vital y algunos trabajos en el campo nos aportan elementos de juicio para avanzar en esta dirección.

Las formas emergentes de socialización y acción colectiva del mediactivismo, la tecnopolítica, los movimientos en red o el activismo digital (Occupy Wall Street, Nuit Debout, el 15M, Yo Soy 132, la Revolución de los Pingüinos) perfilan hoy nuevos procesos distintivos de participación y autonomía de la cultura en los modos contemporáneos de ejercicio de la ciudadanía que deben ser repensados desde una perspectiva materialista, empezando por renunciar a una concepción anquilosada o estática de espacio público. Hoy vivimos un momento de apertura histórica marcada por la incertidumbre y la aceleración del cambio social que requiere de marcos teóricos y un aparataje categorial robusto y consistente. En este marco, la propuesta de Oskar Negt, a propósito de la noción de Espacio Público Oposicional, constituye una alternativa teórica desde la subalternidad y los espacios públicos proletarios que nos puede ayudar a comprender los nuevos movimientos ciberactivistas desde la autonomía de lo social. Si consideramos la constatación de experiencias de largo recorrido como el $15 \mathrm{M}$ en España o el movimiento Occupy Wall Street, observamos que ambas experiencias tienen en común que 
implicaron una alteración radical de las condiciones de enunciación y representación del espacio público, tanto en el plano virtual como desde luego físicamente. La problematización de la relación entre espacio público (físicamente) y esfera pública (plano virtual, simbólico) está en la base del objeto de discusión de la tradición materialista desde Marx. Sabemos que toda tecnología, como producto cultural, es fruto de una mediación objetivadora y una voluntad subjetiva. Esta articulación interna no es escindible, salvo analíticamente. Desde una lectura estructural, y considerando el contexto histórico, como Marx explicara a propósito del fetichismo de la mercancía, la lógica de valorización es la causa explicativa que ilustra la tendencial proyección o imagen ilusoria (en nuestro tiempo las fantasías electrónicas de cierto clickactivismo), como dinámica objetiva de realización. La lógica mercantil, en otras palabras, opera en el plano subjetivo y en la forma material de reproducción. Podemos definir así la alienación como aquella mediación social que segrega, que separa representación y experiencia real, en parte en virtud de varias lógicas de captura que Negt explica en su crítica del Espacio Público Dominante y que en crisis como la del coronavirus pone en cuestión por exigencias de confinamiento, por la inmovilización del sujeto político: sea migrante, proletario o indígena. Así, lo primero que pone en evidencia esta crisis es la inversión entre mercancías que circulan, ahora con dificultades, como el capital, y sujetos confinados: el actor social es inmovilizado como un stock, mientras el objeto mercancía circula como con vida propia. En este sentido, la pandemia pone en cuarentena la propia idea clásica de espacio público y sobre todo la función informativa, no solo por la alarma social que ha generado, sino por las veleidades interpretativas de opinadores y gacetilleros de dudosa fiabilidad que ahora reclaman la intervención del Estado en un tour de force muy propia, como demuestra la historia, del pánico neoliberal. Es lo que podemos calificar como la mediatización y dialéctica del botín y la salud pública que tiene lugar normalmente en momentos de crisis extrema y aguda inestabilidad social. Ahora bien, con la situación de alerta y emergencia sociosanitaria cabe hacer otras lecturas pensando a largo plazo y en profundidad el acontecer. Desde que Ulrich Beck advirtiera que en las sociedades complejas, en la era de la globalización y la conectividad total, hemos de aprender a gestionar lo que denominara la sociedad de riesgo, un incremento de la incertidumbre y las amenazas planetarias que trascienden las tradicionales fronteras y espacios territoriales viene marcando la agenda pública, sin que la teoría y práctica de la acción política haya madurado en sus lógicas de reflexividad y proyección, constatada esta 
nueva dinámica de reproducción. En este escenario, los medios de comunicación cumplen un papel crucial en las formas de gobierno y articulación social, pues pueden contribuir a representar adecuadamente los riesgos y amenazas reales y concretas, además de identificar las alternativas y soluciones para un control social democrático de pandemias como la que vivimos. Si, como analizara el sociólogo alemán, las constantes de una sociedad sometida a fuertes riesgos y a procesos de individualización radical debilitan las formas de equilibrio y reproducción de la vida en común, el papel difusor de pánico moral o salud pública de las noticias de las catástrofes ecológicas, las crisis financieras, el terrorismo o los conflictos bélicos son factores determinantes en la construcción de los horizontes de progreso y exigen, por lo mismo, una decidida intervención política en consecuencia. Así, si analizamos la crisis del coronavirus en términos de Cultura Pública y Democracia Social, observamos que, en países como España, con déficits notorios en la construcción del Estado, marcada por una historia de absolutismo y negación del dominio público, la crisis epidemiológica cuestiona aspectos sustanciales del modelo de gobierno que conviene considerar en detalle. O pensemos en Chile, cuna o laboratorio del neoliberalismo. Esta situación actualiza la doctrina del shock, en este caso para su impugnación. Por ello, cabe pensar que la gestión de la crisis de la pandemia representa el fin de los límites y regulación del Estado social y democrático de derecho ante la exigencia de expansión del espacio vital de reproducción y acumulación del capital financiero internacional imponiendo, como sostenemos a modo de hipótesis, el estado de excepción como regla, frente a toda contractualidad o legitimación democrática, lo que ya viven por cierto los migrantes en situación no regularizada. Entre la forma y la fuerza, entre la regla y la excepción, entre la cooperación y la desconfianza, entre la transparencia y la ocultación, la sociedad de vigilancia, tal y como la piensa Mattelart, nos sitúa pues poco a poco a la multitud como potencialmente sospechosa, convertidos en intocables, criminales, potenciales terroristas o apátridas de un régimen que, conforme a su racionalidad, tiende a excluir a toda la ciudadanía universal.

En este sentido, desde una perspectiva crítica, con las crisis de emergencia por catástrofes o repuntes epidemiológicos debemos reformular la doctrina dominante de seguridad pública, comenzando por trascender la visión estadounidense de la seguridad como el arte de la guerra por un concepto de seguridad como red de apoyo mutuo ante las amenazas, en virtud de la necesaria solidaridad ante epidemias como la soledad y el abandono de los sectores 
vulnerables, los primeros en sufrir las catástrofes como se pudo comprobar con el huracán Katrina en Nueva Orleans. La amenaza de la guerra bacteriológica, a todas luces más que inminente, y las tensiones de guerra económica y ciberguerra entre Washington y Pekín dibujan además un escenario poco o nada proclive a la cultura de paz, máxime cuando coincidiendo con el coronavirus se ejecutan maniobras como Defender Europa 20, con una clara voluntad militar de alcanzar los objetivos políticos estratégicos de la Casa Blanca por otros medios. Por otra parte, el recurso a armas biológicas y la doctrina de guerra total no es nada nuevo. Recordemos las acciones imperialistas del Departamento de Estado contra Cuba (dengue, fiebre porcina, sabotaje de cultivos) o la exportación de armamento con la construcción de la red de terrorismo internacional más amplia en la historia del mundo por parte del complejo industrial-militar del Pentágono, tal y como revelara en sus investigaciones Edward Herman. Considerando la filosofía de la OTAN, que la UE asume acríticamente, todo análisis de las políticas públicas en nuestro tiempo debe cuestionar por tanto, desde una perspectiva democrática, las tesis que impugnan la biopolítica contemporánea por la criminalización de las formas de resistencia de la ciudadanía que vienen desplegándose con especial intensidad desde la década de los ochenta a lo largo y ancho del mundo. De ello me he ocupado ampliamente, para el caso de América Latina, en "Golpes Mediáticos" (CIESPAL, Quito, 2016) y "La guerra de la información" (CIESPAL, Quito, 2017). Ahora, lo que estamos viviendo no solo es la vulnerabilidad de la vida humana, ni el alcance global de toda situación de emergencia 0 catástrofe por venir, sino singularmente la fragilidad del sistema económico internacional. De hecho, esta crisis nos muestra una forma ya habitual de producción de valor. Cuando hablamos de la acumulación por desposesión no es solo una lógica que evidencia el recurso a los bonos basura para mantener o ampliar la tasa de ganancia, o procesos como la supresión del derecho a la ciudad con las intensivas dinámicas de gentrificación y segregación espacial, sino, sobre todo, la artificial dinámica de producción de procesos especulativos con las guerras o las crisis humanitarias que hacen posible las operaciones de Wall Street, por el que se suspenden los derechos fundamentales, imperando la lógica darwinista de selección natural, conforme a la lectura del liberalismo radical, más allá o al margen de la ley, en un proceso que empezó con la información confidencial y las filtraciones interesadas en la era Reagan y hoy ha evolucionado hacia la planificación de macroeventos mediáticos con los consabidos efectos sobre cotización, 
deuda pública y desarrollo de sustanciosos beneficios de los amos del mundo financiero y de la información.

Una de las conclusiones más evidentes de los estudios sobre las formas de hegemonía en la comunicación contemporánea es la imperiosa necesidad del sistema de comando integrado de imponer y propiciar la devastadora lógica de dominio, o seguridad total, colonizando la esfera pública y extendiendo la política de la información de las "bellas mentiras" como relato único y verdadero de los acontecimientos históricos para reproducir la lógica darwinista del ordoliberalismo. Y ello, incluso, a condición de planificar y producir masivamente programas de terror mediático y militar para cubrir los objetivos imperiales, anulando todo resquicio de crítica y pluralismo informativo en la comprensión de los problemas fundamentales de nuestra sociedad. De aquí la necesidad de una mirada sediciosa sobre la política informativa que guía y proyecta los intereses creados del Imperio con la extensión tecnológica del algoritarismo. Sólo si subvertimos nuestra posición de observadores y hacemos un sereno y agudo análisis sobre las formas de producción del consenso en las democracias occidentales, tal y como lo hace en su libro "Un mundo vigilado" Armand Mattelart, podremos entender cómo en la reciente historia existe una delgada línea roja, un hilo histórico que vincula las formas de gestión de la opinión pública del modelo angloamericano con el sistema de propaganda de Goebbels, una lógica instrumental que liga el régimen fascista con la voluntad de poder del gobierno imperial, a Dovifat y la dirección de la opinión pública con Lippmann y la producción del consentimiento, y la política de terrorismo y delaciones nazi con la red de inteligencia y videovigilancia global que extiende el complejo industrial-militar del Pentágono. Tras la lectura atenta del nuevo volumen de Ignacio Ramonet sobre La sociedad vigilada o el trabajo de André Vitalis y Armand Mattelart De Orwell al cibercontrol, el campo académico de la comunicación debería replantearse seriamente la función que desempeña en este escenario la cultura BIG DATA. Más aún, ¿qué consecuencias tienen los conflictos latentes entre la UE y EE.UU. por el dominio de los flujos de información y el gobierno de Internet? $\mathrm{O}$ ¿en qué sentido podemos hablar de un modelo global de Sociedad de la Información si los principales actores transnacionales de la industria telemática están participados por los intereses estratégicos de la industria estadounidense y el complejo militar del Pentágono?. Sabemos que las redes telemáticas están subvirtiendo la democracia, siempre lo han hecho. Ahora, las redes electrónicas y los nuevos sistemas de comunicación son manifiestamente incompatibles con el 
diálogo político; la fragmentación y dispersión del espacio público es hoy la norma; el control de las redes a través de programas como Echelon amplía los sistemas de vigilancia y dominio del espacio privado de la comunicación; mientras que la instrumentación mercadológica de la democracia digital en los procesos de elección vacía de contenido público la participación ciudadana. Para resumir, y a modo de conclusión, como en otros momentos de crisis y bifurcación histórica, la pregunta, por impertinente, que conviene formular, siempre intempestivamente, como corresponde a una visión materialista, es quiénes se benefician del control de la opinión pública ante crisis como la pandemia. El neoliberalismo sabemos que fue impuesto con terrorismo de Estado: de Pinochet a Piñera. Y también somos conscientes que la viralidad de las noticias engrasan la cuenta de resultados de los medios mercantilistas. He ahí la prueba de Trump y el Washington Post. Por otra parte, la explotación total requiere hoy de la guerra híbrida por las dificultades del capital acumulado de realizarse en esta fase especulativa y rentista. Ya conocemos las lecciones de Thomas Hobbes. Esto es, este tiempo de emergencia es propio de la doctrina de seguridad total por encima de toda veleidad informativa. Añadamos a este razonamiento que hace tiempo, quizás desde la primera Guerra del Golfo, que sabemos que la superioridad informativa es prescriptiva del orden y lógica del control social. Y que terror y valor son del mismo campo semántico en el capitalismo zombie que vivimos. La lógica vampírica del capital, como bien ilustrara Marx en El Capital, no para de acumular cadáveres, al tiempo que despliega una calculada política de terrorismo informativo para que, por encima de todo, nadie mire a Wall Street. Paradojas de la toxicidad de nuestro tiempo. Todo, en suma, es una cuestión de botín. Pero, hoy, como ayer, atentos al contagio, y al arte de la imitación, una lección está clara en esta crisis, como en otras experiencias anteriores, la deriva del contagio, natural o virtual, no es solo programable por la industria cultural. Es también una cultura de la emboscada de las multitudes. La historia así lo demuestra. En definitiva, la instauración de este sistema hegemónico de dominación espectacular ha supuesto un cambio social tan profundo que, lógicamente, ha transformado el arte del gobierno. Hoy la banalización de la guerra como instrumento ético de las viejas naciones imperiales es reactualizada desde una cultura mediática diferente, en la que la "pantalla total" que coloniza los medios de vida adquiere una relevancia insospechada: la de representar la fuerza del poder hegemónico, la de reproducir la potencia de la soberanía, sobrecodificando la capacidad del Imperio de garantizar policialmente el orden al servicio del 
derecho y la paz, alterando así radicalmente las condiciones de organización y planeación de la acción política. Si Clausewitz hizo célebre la distinción entre táctica, como empleo de la fuerza en combate para alcanzar la victoria, y estrategia, como el empleo de las victorias a fin de alcanzar los objetivos de la guerra, hoy la solución de continuidad entre una y otra es prácticamente indiscernible en la definición de la escalada de intensidad, baja o alta, de los conflictos, al punto que toda la vida social aparece como un problema estratégico de seguridad pública, en una concepción de la guerra, representada en los medios, total y prolongada, pensada incluso como la anticipación calculada de previsibles puntos de intervención conforme a lo que Debord denomina "lo espectacular integrado" en la llamada guerra preventiva. Así, la sofisticación tecnológica y la pregnancia de una retórica de escenificación militar espectacularizada, característica de los sistemas imperiales, envuelven hoy los discursos informacionales de la aldea global. En esta operación, el discurso espectacular es un discurso terrorista. De manera que la construcción noticiosa del pánico moral de las multitudes impulsada por la prensa valida la hipótesis de Klein sobre la doctrina del shock como pérdida de sensibilidad y conciencia de la situación real vivida. Del Chile de Pinochet a la guerra de Irak, pasando por los conflictos de los profesionales del silencio, las ideas de Milton Friedman pueden así llevarse a efecto en una situación de estado de emergencia en el que, como critica Agamben, la excepción es la norma y la mediación informativa una comunicación del pavor orientada a reproducir la narrativa estática del neoliberalismo, esto es, el aislamiento físico, psicológico y, claro está, político contra las medidas impuestas de expropiación. Frente a esta lógica devastadora del capital rentista, es precisa la lucha democrática por la información. Comenzando por las redes digitales. De acuerdo con Pierre Lévy, la transparencia financiera ciberdemocrática exige luchar contra la corrupción impulsando medidas y soluciones de control presupuestario por la función pública, inspirar la confianza de los ciudadano e implicar a la ciudadanía en la administración de la prosperidad, definiendo otra comunicación del riesgo y la dinámica económica en lo que debería ser una política que pase de lo reactivo a lo proactivo, especialmente pensando en los agentes implicados en la mediación de los abusos especulativos. Estas son algunas de las pocas certezas que cabe defender en la actual coyuntura histórica. De algunas de ellas me ocupo en Marxismo y Comunicación, en especial en lo concerniente a la revolución digital y sus implicaciones. A mi juicio, la primera y principal tarea que es preciso acometer es recuperar la potencia de la perspectiva materialista en el 
estudio de la comunicación contemporánea. Aprendimos con Benjamin que la curiosidad intelectual es una de las pocas cosas que eleva la vida humana por encima del nivel de la farsa. Obedece al principio de autosuperación, como nos enseña Castoriadis a propósito de la creatividad constitutiva del homo loquens y del homo faber. Pero hoy requiere nuevos métodos de intervención asumiendo que la nueva economía cultural subjetiviza los objetos y mercantiliza los sujetos. Crece, como argumenta Verdú, la subjetividad del objeto y la objetividad del sujeto proyectando a futuro, con la robótica, el poshumanismo de los SOBJETOS. La constatación de esta imposición del universo del fetichismo de la mercancía valida la pertinencia anticipada por la Escuela de Frankfurt de deconstruir la desublimación represiva y la falsa libertad, hoy constatables en la cibercultura, para explicar las formas complejas de dominación en favor de un abordaje psicoanalítico de control y gubernamentalidad de los deseos, de producción, como pensó Herbert Marcuse antaño, de la conciencia y la necesidad. Hemos escrito en Ciudadanía Digital y Desarrollo Local (Bibilioteca Nueva, Madrid, 2019) que la banalización de lo privado que acompaña el auge de las redes es uno de los efectos colaterales de nuestra falta de control sobre algo que nos ha pertenecido en exclusiva durante siglos. Pero empiezan a observarse movimientos transgresores que desbordan, de forma creativa, la administración comunicativa. El reto que tenemos, desde la práctica teórica, es contribuir, de acuerdo con Hernández Busto, al paso de un mundo donde recordar era la excepción (y olvidar era lo natural) a un orbe digitalizado donde la tecnología invierte esos términos. Reconociendo el cambio en las formas de relación entre público, medios y canales de información, la vindicación del softpower elude pensar este necesario compromiso intelectual, complementario de las demandas de la UNESCO sobre diversidad, pero que apunta al núcleo constitutivo del poder de los GAFAM: la organización oligopólica de la estructura comunicacional, de la memoria y la representación. En otras palabras, frente a la banalización de la lógica de la comunicación como dominio, el retorno a Atenas es afirmar la Phronesis y la sabiduría práctica de la economía moral de las multitudes conectadas, problematizando los dispositivos, políticas y lógicas dominantes de representación. Pero también la cultura académica contraria a una filosofía de la praxis por una mala entendida concepción del conocimiento basada en la división social del trabajo, cuando más factible es y accesible resulta el saber socialmente necesario. No se trata, en fin, dada la deriva actual, pensar la cibercultura como un permanente proceso de innovación y mejora del bienestar 
público, sino antes bien, como plantea Subirats, se trata de posicionarse desde la democracia radical participativa ante los dilemas de la mediación digital que acompañan al nuevo espíritu del capitalismo. En este marco contradictorio, la intensificación de las formas participativas de gestión local que vienen extendiéndose parece un proyecto y realidad inevitable. De los núcleos de intervención participativa y consejos ciudadanos, a las Iniciativas Legislativas Populares, de los referéndums o foros ciudadanos frente al extrañamiento del paradigma representacional a las asambleas de zonas, tales experiencias afirman la VIVENCIA PARTICIPATIVA que apunta a la necesaria construcción de una nueva COMUNICACIÓN para el BUEN VIVIR. El grado de radicalidad democrática de estas iniciativas, por lo general aisladas y episódicas, depende de la conciencia y voluntad política. En este marco, la teoría crítica de la mediación se ve impelida a definir nuevos anclajes conceptuales y una ecología del saber comunicacional pensada desde el Sur y desde abajo, considerando la centralidad que, hoy por hoy, adquiere el trabajo inmaterial y, más concretamente, las nuevas tecnologías digitales, en los procesos de intercambio y reproducción social ampliada que anteceden y atraviesan toda posibilidad o forma de convivencia. Pues con tal proceso no sólo han entrado en crisis las formas de gubernamentalidad y las lógicas de concepción del desarrollo herederas del difusionismo iluminista. Las redes y el lenguaje de los vínculos definen nuevos cronotopos y puntos de condensación de la experiencia del sujeto moderno que deben ser repensadas desde una cultura de investigación dialógica y una concepción abierta del acontecimiento, dada la ruptura o discontinuidad histórica experimentada en la producción mediática contemporánea. En otras palabras, en el nuevo horizonte cognitivo, la política de la ciberdemocracia debe plantearse como una Economía Política del Archivo, como una crítica metacognitiva de la captura de la experiencia vivencial, comenzando con los indicadores de inclusión digital y concluyendo con los modos de compartir y socializar el saber sobre lo social donde emergen tensiones y aperturas, contradicciones y problemas como el perfilado y la videovigilancia, la mercantilización y biopolítica de lo común, la crisis de los modelos tradicionales de organización, la heterotopía y explosión de la diversidad en el ágora virtual y la normalización, la remediación y el crowsourced en la generación de los datos ciudadanos, la individuación y la incultura o falta de competencias ciudadanas en el uso inteligente de la información, la infoxicación y apropiación corporativa de los datos públicos o la colonización de la memoria externa, o exomemoria, por los criterios de clasificación de Google. En suma, en la era de 
Cosmópolis, de David Cronenberg, en la era de Cosmocapital, la pregunta por capciosa, y no menos relevante, de un escenario complejo e intrincado como el que hemos descrito es QUÉ HACER. La reflexividad sobre el nuevo horizonte cognitivo del marco histórico-cultural exige repensar, primero, aportes fundamentales para la crítica. Esto es, pensar el papel de la crítica, los contornos y perfiles de la sociedad posmoderna liberal y la articulación de la acción y la razón en tiempos de libre comercio a la hora de comprender el proceso de configuración del trabajo abstracto y la función estructurante de la mediación social con las redes digitales. En este empeño, la crítica necesita deconstruir con capacidad de asombro y atención por lo auténtico las formas autónomas de participación en la cultura digital para denunciar, tal y como advierte Zizek, que la verdadera utopía es la creencia de que el sistema mundial de la comunicación como dominio puede reproducirse de forma indefinida. Si algo dejó claro hace más de 150 años Marx, en su primer volumen de El Capital, a todos los lectores de su época es, justamente, que la única forma de ser verdaderamente realistas es prever lo que, en las coordenadas de este sistema, no tiene más remedio que parecer imposible y hoy, en la galaxia Internet, sabemos que, como los universos virtuales, aquello que era materialmente imposible, hoy resulta del todo factible y realizable en cualquier momento. Está por ver cómo lo construiremos juntos y qué trabajo será capaz de desplegar la academia en esta dirección. 